On March $318 t, 1903$, Mr. C. Braine anaesthetist, I enucleated the prostate entire in its capsule easily, the urethra being left intact. Nine minutes only elapsed from commencing the suprapubic incision till the prostate was removed from the bladder. Though there was scarcely any bleeding during the operation, owing to the restlessness of the patient there was for several days some oozing, giving rise to clots which caused irritation of the bladder and necessitated removal of the sutures, so that the suprapubic wound gaped and was slow in healing. Small quantities of uriue passed naturally almost daily, but not in quantity till May roth. A sharp attack of rheumatism retarded his recovery, but the patient

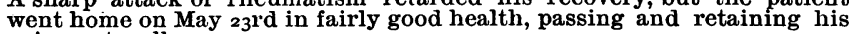
urine naturally.

The prostate, which is symmetrically enlarged, with small nodulated outgrowths from each lateral lobe in the bladder, weighs $2 \frac{1}{2} \mathrm{Oz}$.

A gentleman, aged 7I, consulted me March 28th, rgo3, for prostatic troubles. Catheter employed for twenty years, not a drop of urine passed naturally for last eighteen years. Calculi removed by crushin on three occasions by London specialist: double castration by another London surgeon for cure of prostatic troubles in 1897, but without any amelioration of his symptoms. Slight paralytic stroke in January rom which he completely recovered, but has had a nurse ever since. Extremely feeble and hysterical: breaks down and weeps without apparen cause. Patient's condition mos pitiable. Haematuria from time to time. Urine contains much pus and blood, and is most offensive; bladder can contain only small quantity; hence catheter used half-hourly day and night. Enormous enlargement of prostate per rectum, soit, smooth, bilobed, movable. Cystoscopy on March 3oth revealed an enormous outgrowth of prostate in the bladder.

On April rst, Mr. Wylie assisting, I enucleated the prostate entire in its capsule, leaving the urethra behind. The prostate projected into the bladder in the form of a cone, the urethral orifice being shaped like the crater of a volcano. Considerable force had to be employed to separate the capsule from the sheath. After delivery of the prostate as a whole into the bladder, owing to its large size, the lobes had to be separated to facilitate its removal though it was very sort and spongy. Only eleven minute elapsed from commencing the operation till the prostate was delivered from the bladder. There was scarcely any bleeding or shock. The patient made an uneventul Urine passed naturally April 26th, and the wound was dry May 5 th. He was quite overcome with joy at passing urice naturally again after eighteen vears of complete catheter life. Went home May irth, and is now in excellent health, able to retain as he ever did.

The prostate (Fig. 4), which weighs $8 \frac{1}{4} \mathrm{oz}$. , is a very large one, the second largest I have removed. The right lobe (A) is enormously enlarged, the left lobe (B) less so. The case is, indeed, a remarkable one, showing what wonderful results may be accomplished by this operation even when the patient is almost moribund.

\section{CASE XLIV.}

General X., aged 63, had consulted me on and off for seven "years for (a) stricture, and latterly to enlarged prostate. Internal urethrotomy ten years ago; since then steel sounds passed periodically. Decided prostatic symptoms for last three years ? frequent attacks of cystitis ; catheter employed and bladder washed out; for last four months symptoms very distressing. Cystoscopy on March 24th. Igo3, revealed considerable outgrowth of both prostatic lobes in the the stricture and prostatic en margement.

On April ist (Dr. Dudley Buxton, anaesthetist) I opened the bladder suprapubically, and removed the prostate, both lobes coming awa; separately, the urethra being left intact; scarcely any bleeding or shock. Uninterrupted recovery, some urine passing naturally April 5th, and wholly in this way April 2rst. The patient went home May rst, retaining and passing urine naturally, and in better health than for many years.

The prostate weighed I oz., and was rather hard.

\section{CASE XIV.}

A member of the medical profession, aged 61, with prostatic symptoms for four years. Retention two and a-half years ago, relieved by catheter by $\mathrm{Dr}$ Beaver, Sturminster Newton. Had double vasectomy performed by a well-known provincial surgeon; no relie therefrom. Practically the whole of the urine by catheter for eighteen months; several attacks of cystitis. 'Prostate decidedly enlarged per rectuin, rounded, soft, tense, smooth. and movable. Cystoscopy on March 4th revealed well-marked outgrowths of both prostatic lobes in the bladder, particularly of the left.

On April 6th, r9o3, I removed the prostate entire in its capsule, the lobes opening out along their superior commissure, leaving the urethra unirjured. The patient was only twenty-three minutes on the operating table, and only seven minutes elapsed from commencing the suprapubic wound till the prostate was delivered from the bladder. Scarcely any bleeding or shock. Several ounces of urine were passed naturally during the first few days; then all the urine by the suprapubic wound for several days. The latter finally closed May 3rd. During the first ten days the wound was covered by much phosphatic grit,which required removal twice daily. and some grit was also passed per urethram with the urine. The patient left for the country May 5 th, and is now in excelleut his his urine naturally. I under-

me has recently read a paper

The prostate is an excellent specimen of non-symmetrical enlargement, the left lobe being much more bulky than the right. It weighed $\mathrm{I} \frac{\mathrm{a}}{4} \mathrm{oz}$.

1 BRITISH MEdical JOURNALFERENCE. 8th, 1902; April r8th, 1903.

\section{SOME POINTS IN THE PATHOLOGY AND TREATMENT OF PROSTATIC OBSTRUCTION,}

WITH AN ACCOUNT OF THIRTY-THREE OPERATIONS FOR ITS REMOVAL.

BY W. BRUCE CLARKE, M.B., F.R.C.S

Surgeon to St. Bartholomew's Hospital ; late Surgeon to St. Peter's Hos pital for Stone; Examiner in Surgery, University of Oxford, etc.

Those who have read the critical remarks of Sir Winiam Thomson on the removal of prostatic adenomata in the British Medical Journal of May 3ist, ig02, will, I am sure agree with me that his views are in the main correct and much to the point, but it appears to me that he has only touched one side of the disease to which we apply the term prostatic obstruction. To my mind, it is of some importance that in clinical descriptions of this condition we should employ the term prostatic obstruction, and avoid the term which is in more general use-namely, "prostatic enlargement;" and for this reason: that in many of the cases in which the patient finds it quite impossible to empty his bladder, there is no prostatic enlargement.

One of the main points to which attention is called in this paper, to which I just referred, is the question of how much of the prostate is removed by those who have performed prostatectomy; in other words, Is prostatectomy really a removal of the whole gland, or is it not? Amongst others, I an referred to as having stated that I have removed the "whole prostate ;" and it may perhaps tend to clear up our ideas on this subject if I state briefly how it was that I arrived at the notion that I had removed the whole of the organ. It was because after I had shelled out an enlarged mass from the prostate by the suprapubic route I found that I could get my finger down as far as the triangular ligament, and no trace of prostate could be detected, and further when the patient was restored to health, a digital examination of 
the rectum by myself and others failed to discover any indication of prostatic remains.

Such a test may be sufficient for clinical purposes, and, coupled with the patient's condition, may be regarded as ample proof that his enlarged prostate has disappeared, but it does not prove that no remnant of the gland remains behind. This is difficult enough to ascertain after a necropsy has been performed and microscopic sections have been carefully prepared and it camnot be proved without it. Sir William Thomson evidently believes that such a remnant of prostatic tissue was left behind in his case, for he says, "I removed two adenomatous tumours, leaving behind, I believe, a layer of prostatic tissue representing the gland proper, but squeezed out of recognition by the pressure of the pathological growth."

Granting that this is the condition of things that exists when prostatic growths are shelled out, is it certain that all cases of prostatic obstruction are caused by adenomatous tumours in various stages of growth? To this query I would make the emphatic reply, "No" and my reasons for this statement are as follows. There is a certain class of prostatic obstruction, in which the prostate is not greatly enlarged, perhaps not enlarged at all, and if an operation is attempted, the prostate will be found to be hard and fibrous, impossible to enucleate and difficult to remove, but when it is removed, if the term removal can be properly applied to what is but a partial excision, the results are very successful. If the excised portions are submitted to microscopic examination they will be seen to consist of partially atrophied glandular elements and fibrous tissue in varying proportions with but little of the original muscular tissue of the prostate.

These hardened prostates have been spoken of by some authors as if they were merely one stage in the life-history of an adenoma, but to my mind it is difficult to understand how this can be the case. I would rather regard them as depending on an entirely different pathological process. Their appearance indicates that they have been caused by a chronic inflammatory process which has gone on to sclerosis and destruction by strangulation of the prostatic gland elements, and hence the view of the French school, headed by Guyon, that prostatic enlargement is part of a general senile change.

An excellent summary of what is to be said on behalf of this view is put forward by Casper, ${ }^{1}$ who attacks Guyon's theory as published by his pupil Launois, that prostatic hypertrophy is always accompanied by arterio-sclerosis, and is, indeed, a result of that disease. According to this theory, not only in the prostate itself, but throughout the whole urinary tract, there is well-marked degeneration of the arterial coats, and as a consequence of this condition a hypertrophic condition of the prostate and bladder walls supervenes. This latter condition is assumed to be due to a neoplastic growth, and not to mere muscular hypertrophy, which is renderer necessary by the mechanical resistance that is offered by the prostatic hypertrophy.

In refutation of this theory Casper gives the results of his examination of 24 cases of prostatic hypertrophy, and states that in only 8 cases out of the 24 did he find arterio-sclerosis of the renal vessels, and in only 5 of these 8 were the prostatic vessels involved as well.

In only 2 cases was there simultaneous disease of the renal, vesical, and prostatic vessels. On the other hand he found 4 cases of arterio-sclerosis of the kidney in which the prostate was not involved at all. Every one of the 24 cases of enlarged prostate were above 50 years of age, a fact which gives additional weight against Guyon's theory, for arterial disease is so common after this period of life that the small number of cases in which it occurred is more readily explicable as a mere coincidence than as an indication of any causal relationship between these two pathological conditions. Casper makes a further and even more significant remark upon the subject when he points out that the results of arterio-sclerosis elsewhere in the body are degeneration and not hypertrophy, and it is extremely improbable that the prostate should prove an exception to this rule. My own observations of a considerable number of the prostates of elderly men fully bears out Casper's views. But more than this, there is a very close analogy between the changes that occur in the prostate as age advances and those which are seen in other organs. If the female breast is examined in early adult life-for example, 2I-there is far more fibrous tissue than glandular, but the glandular tissue is well formed and regular in outline. If an ordinary fibro-adenoma of the breast is submitted to microscopic examination the first thing that strikes one is the enormous proportion of glandular tissue as compared with that which exists in a similar area of healthy breast tissue, but it is ill-formed, and a precisely similar condition occurs in a prostatic adenoma. If we examine a case of chronic mammary induration, which is often spoken of as chronic mastitis, it seems to bear some general resemblance to the harder prostatic growths; and the appearances of the parenchymatous and fibrous goitres present an almost analogous series of changes, and when we recall the fact that the prostate is enveloped by a firm capsule which is reinforced on one side by the firmly-resisting. triangular ligament, it is not surprising that its natura appearance should be altered by its adenomatous overgrowth and make the changes which it has undergone difficult to follow.

No doubt prostatic adenomata may and do often occur in the same individual who is the subject of prostatic sclerosis but the two processes are essentially different and depend on different causes; the one is essentially a tumour formation, the other possibly the result of inflammation or at least of some form of irritation.

If further evidence be needed to prove the fact that prostatic obstruction does not depend on one form of growth, we can turn to the writings of many authors. One will be sufficient for our present purpose. Albarran and Hallé describe the enlarged prostate as follows: In it can be seen soft glandular hypertrophy, hard glandular hypertrophy, hard fibrous hypertrophy, circumscribed neoplasms, fibromata, myomata, adeno-fibro-myomata. "We are entirely ignorant of the true nature of these lesions from a pathological point of view, and we find only hypotheses badly supported by facts."

Before passing on to the consideration of the treatment of these conditions, each of which should, I contend, be treated by appropriate means, and not necessarily by the same procedure, there is another change in the prostate which is not infrequently met with in advanced life, and which may be briefly alluded to, namely, the presence of a considerable number of enlarged veins in connexion with this organ.

The prostatic plexus of veins is described in works on anatomy as surrounding the prostate, and so undoubtedly it does, but the surgeon is familiar with the prostate which bleeds only too readily when an instrument is passed into the bladder, or when an attempt is made to attack it by operation on its bladder aspect, and in no inconsiderable number of such cases the veins of the trigone and those which surround the vesical orifice of the urethra are actually varicose, anel may cause death from haemorrhage into the bladder.

There is, I am fully aware, nothing which is specially novel in this description which I have just given of the prostate in advanced life, but what $I$ am anxious to insist upon is the fact that there are at least three conditions of prostatic obstruction that are quite independent one of the other, and though often associated together they really depend on separate pathological conditions. Because they are often associated together in the same individual, they have been regarded as merely incidents in the life-history of an enlarged prostate, instead of separate diseases of the prostate, which occur in advanced life.

Superadded to these three conditions when cystitis supervenes upon prostatic obstruction there is a fourth condition, namely, inflammation and congestion of the mucous membrane surrounding the urethral orifice. All these features must be carefully taken into account if our operative treatment is to be placed on a rational basis, and it is for that reason that I have divided the cases which I am placing before you this evening into separate series (See Tables p. 8).

In the series of cases which is here presented, I have included all the cases of prostatic obstruction in which I have removed any portion of growth from the prostate for the relief of that condition, and they are divided into six series (I) Prostatectomy-McGill's operation; (2) the removal of pedunculated middle lobes; (3) prostatectomy in two stages : (4) shelling out of adenometa; (5) partial removals of fibrous prostate; (6) operations on vascular prostates. I will briefly allude to certain important features of each of these groups:

I. I have included together my earlier operations on the prostate which I began after I had seen McGill's cases, and heard his paper at Leeds in 1889 under the title of McGill's operation. These operations-seven in number-differ fron my subsequent ones inasmuch as an attempt was made to remove wliat was deemed to be the obstructing portion of the prostate, whether it was hard and fibrous or adenomatous in character, and with more or less success; and the results were, as will be seen by the accompanying tables, hy no 


\section{I.-McGill's Operation.}

\begin{tabular}{|c|c|c|c|c|c|}
\hline No. & $\begin{array}{l}\text { Name } \\
\text { and Age. }\end{array}$ & Where Performed. & Date. & Immediate Result. & Ultimate Result. \\
\hline $\begin{array}{l}\mathbf{1} \\
2 \\
3 \\
4 \\
5 \\
6 \\
7\end{array}$ & $\begin{array}{l}\text { J. B., } 69 \\
\text { C. P., 65 } \\
\text { J. J., } 62 \\
\text { P. P., } 66 \\
\text { J. M., } 69 \\
\text { J. S., } 69 \\
\text { E. R., 72 }\end{array}$ & $\begin{array}{l}\text { West London Hospital } \\
\text { St. Bartholomew's Ḧospital } \\
\text { ", } \\
\text { ", }\end{array}$ & $\begin{array}{l}\text { Oct., r889 } \\
\text { May," } 1893 \\
\text { June, r893 } \\
\text { :Sept., r893 } \\
\text { June, r895 } \\
\text { Jan., r896 }\end{array}$ & $\begin{array}{l}\text { Healed in just over month ; no residual urine } \\
\text { Healed in six weeks ; no residual uriue } \\
\text { Stone crushed; symptoms continued ; bladder } \\
\text { opened; piece of prostate removed } \\
\text { Bladder irritable; stones removed and piece of } \\
\text { prostate improved } \\
\text { Died; pyonephrosis three weeks after operation } \\
\text { Stone removed at same time: died : pyonephrosis } \\
\text { A large piece removed; less irritation; some } \\
\text { residual urine }\end{array}$ & $\begin{array}{l}\text { Well six months later. } \\
\text { Well eight months later. } \\
\text { Four months later no residual urinc. } \\
\text { A year later fairly well, but urine some- } \\
\text { times foul, } \\
\text { Lost sight of. }\end{array}$ \\
\hline
\end{tabular}

\section{II.-Removal of Pedunculated Middle Lobe.}

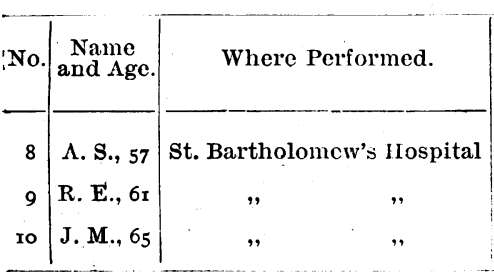

\begin{tabular}{|c|c|}
\hline Date. & Immediate Result. \\
\hline Nov., 1892 & $\begin{array}{l}\text { Stone in bladder and middle lobe removed subcu- } \\
\text { taneously } \\
\text { May, r896- } 89 \\
\text { Mecovery obstruction; removal middle lobe; } \\
\text { Old stricture ; foul urine ; septicaemia ; death }\end{array}$
\end{tabular}

III.-Prostatectomy in Two Stages.

Cases ir to ${ }_{7}$ inclusive, all recovered from operation (vide BRITISH MEDICAL JourNaL, rgoo, vol. ii, p. Ir82).

\section{IV.-Shelling Out Adenomata.}

\begin{tabular}{|c|c|c|c|c|c|}
\hline No. & $\begin{array}{c}\text { Name } \\
\text { and Age. }\end{array}$ & Where Performed. & Date. & Immediate Result. & Ultimate Result. \\
\hline x8 & H. N., 67 & St. Bartholomew's Hospital & Aug.,: 1894 & Sessile middle lobe containing adenoma ; bladder & A month later no residual urine; a little \\
\hline $\begin{array}{l}19 \\
20\end{array}$ & $\begin{array}{l}\text { G. E., 62 } \\
\text { J. G., } 73\end{array}$ & $\begin{array}{ll}" & , \\
, & ,\end{array}$ & $\begin{array}{l}\text { Ja.n., r9o0 } \\
\text { May, r9oo }\end{array}$ & $\begin{array}{l}\text { cauterized } \\
\text { Residual urine about I2 oz.; adenomata shelled } \\
\text { out } \\
\text { Residual urine } 8 \mathrm{oz} \text {; some cystitis; fibromyo- }\end{array}$ & $\begin{array}{l}\text { Long convalescence; two months after } \\
\text { leaving hospital no residual urine. } \\
\text { Five months later no residual urine. }\end{array}$ \\
\hline $2 I$ & E. B., 6I & $\begin{array}{l}\text { From New Zealand; } \\
\text { Willett gave anaesthetic }\end{array}$ & April, rgor & $\begin{array}{l}\text { Cystitis and great frequency of micturition ; large } \\
\text { adenoma }\end{array}$ & \\
\hline 22 & J. C., 57 & From Dr. llott, Bromley & Aug.,':1901 & $\begin{array}{l}\text { Three years' trouble ; frequency of micturition; } \\
\text { large adenoma removed }\end{array}$ & $\begin{array}{l}\text { Seen end of roos; well except for occasional } \\
\text { attack of cystitis; holds watcr when sit- } \\
\text { ting or lying, but it occasionally dribbles } \\
\text { away when he walks about. }\end{array}$ \\
\hline
\end{tabular}

\section{V.-Partial Removal of Fibrous Prostate.}

\begin{tabular}{|c|c|c|c|c|c|}
\hline No. & $\begin{array}{l}\text { Name } \\
\text { and Age. }\end{array}$ & Where Performed. & Date. & Immediate Result. & Ultimate Result. \\
\hline 23 & H. O., 60 & From Dr. Edwards, late of & Nov., rgor & Five years' catheterism; residual urine $8 \mathrm{oz}$. & Well; no residual; six weeks after wound \\
\hline 24 & D. T., 55 & $\begin{array}{l}\text { From Dr. Blackwell, Tun- } \\
\text { bridge Wells }\end{array}$ & Mar., 1902 & $\begin{array}{l}\text { Slight trouble four years ; considerable frequency } \\
\text { and catheter one year }\end{array}$ & $\begin{array}{l}\text { Made an excellent recovery in less than a } \\
\text { month : seen well several times since. }\end{array}$ \\
\hline 25 & E. L., 57 & From Surgeon-Major Dilke, & April, rgo2 & Two years' catheter ; no cystitis ; 6 oz. residual & Well in five weeks; seen well in December, \\
\hline 26 & R. T., 55 & St. Bartholomew's Hospital & Nov., rgor & $\begin{array}{l}\text { One year and a half's frequency; occasional } \\
\text { catheter ; residual } 7 \mathrm{oz},\end{array}$ & Well in February, rgoz: no residual \\
\hline 27 & - & $"$ & May, r9o3 & Under treatment & \\
\hline
\end{tabular}

\section{VI.-Vascular Prostate and Trigone.}

\begin{tabular}{|c|c|c|c|c|c|c|}
\hline No.' & $\begin{array}{l}\text { Name } \\
\text { and Age. }\end{array}$ & Where Perform & med. & Date. & Immediate Result. & Ultimate Result. \\
\hline 28 & W. D., 75 & St. Bartholomew's I & Hospital & -Mar., r8go & Cystitis, prostate slightly enlarged; large veins; & Was seen well a few months later. \\
\hline 29 & & $"$ & $"$ & Aug., $189 \mathrm{r}$ & Bottini cautery & $\begin{array}{l}\text { Seen in r8g9; said he had no urinary } \\
\text { trouble and was quite well. }\end{array}$ \\
\hline 30 & J. C., 72 & ", & $"$ & Nov., 1891 & $\begin{array}{l}\text { Severe bleeding; veins large near urethral orifice; } \\
\text { cautery }\end{array}$ & $\begin{array}{l}\text { Made a good recovery and was well a few } \\
\text { months later. }\end{array}$ \\
\hline $3 r$ & S. C., 50 & " & " & Oct., 1893 & $\begin{array}{l}\text { Very gouty ; haematuria ; mucous membrane ; base } \\
\text { of bladder cauterized }\end{array}$ & $\begin{array}{l}\text { Improved; seen in rooo; says he is fairly } \\
\text { well ; no catheter. }\end{array}$ \\
\hline 32 & M. H., $5^{\circ}$ & " & ", & April, 1899 & $\begin{array}{l}\text { Cystitis; large veins near urethral orifice cauter- } \\
\text { ized }\end{array}$ & $\begin{array}{l}\text { Left hospital improved: said to have died } \\
\text { a few weeks later; cause? }\end{array}$ \\
\hline 33 & R. S., 59 & From Dr.Sydney Bea & eauchamp & June, rgor & $\begin{array}{l}\text { Catheter two years; vesical irritation; large veins } \\
\text { and loose mucous membrane cauterized }\end{array}$ & $\begin{array}{l}\text { Six months later well and comfortable : no } \\
\text { residual. }\end{array}$ \\
\hline
\end{tabular}


means uniformly successful. Three of these cases were quite successful, and enabled the patients to empty their bladders completely without recourse to catheter. Two were moderately successful, that is to say, the condition was improved, but some residual urine was almost always present and a catheter had to be employed from time to time, and two cases died from pyonephrosis and suppression. McGill, in his original paper, which was read at the Leeds meeting of the British Medical Association in 1889 , began by stating that in his opinion the obstruction was caused by the intravesical portion of the prostate, and in reference to this question uses the following words: "We have seen that the cause of the mischief is the intravesical prostatic outgrowth, and this outgrowth must consequently be removed."

When other surgeons began to test McGill's procedure, it soon became evident that his conception of the offending part of the prostate was too limited, and he himself, as his experience increased, was inclined to more complete removal than he at first advocated. All my early operations were undertaken under the notion that there was but one form of prostatic enlargement, which, though it might vary in dimensions, did not do so in its structure, and it is only since I have made a careful examination of a large number of prostates, and especially turned my attention to their microscopic appearances, hardness, vascularity, etc., that I have come to think otherwise, and have by degrees been brought to feel that prostatic obstruction is determined sometimes by one pathological condition and sometimes by another, and that these varieties demand separate treatment. It is only by the careful consideration of these conditions that we can guarantee the success of any operation that is undertaken for the relief of prostatic obstruction.

II. In one sense the removal of pedunculated middle lobes may be included in those cases I have just spoken of, but they form such a distinct set of cases by themselves that I have thought it best to consider them separately. Their removal has been practised and recorded by surgeons from time to time, and is, I believe, an excellent method of treating what is undoubtedly a rare condition. In two of the cases here recorded (one of which by the way was associated with calculus) the result was excellent and the natural power of micturition was regained. In the third case the patient had suffered from a stricture for twenty years and had generally neglected it. His urine was exceedingly foul, alkaline, specific gravity 10I, and as the necropsy proved his kidneys were diseased. The middle lobe was removed, and all went well for some days. but septicaemia supervened, and deposits of pus were found after death in various parts of his body. It is also interesting to note that two flbromyomata:about the size of peas were found bulging into his urethra and obstructing it, so that in all probability had he recovered there would still have been a further source of obstruction to remove later. I now most carefully examine the prostatic urethra in all cases as well as the rest of the prostate in order to be quite certain that everything which is likely to cause an obstruction is removed.

III. After castration and vasectomy had been proved to be no universal panacea for prostatic disease, one's attention was again turned to the prostate as the source of obstruction with a view to seeing if some more certain method or methods could not be devised both for the removal of the source of obstruction and the avoidance of the evil effects of sepsis, and my later series of operations was undertaken. In the British Medical Journal, igoo, vol. ii, p. i182, I published an account of seven operations, all of which were successful, undertaken for the relief of septic prostatic cases under the title of "Prostatectomy in Two Stages," and since that time have performed another operation of the same kind also with success, as will be seen by the table. I need not allude further to these cases except to state that I never suggested or wished to suggest that this operation was generally applicable to cases of prostatic trouble, but have only employed it order to evade the effects of sepsis. To judge from the letters I have received on this subject, there seems to be an impression that I have proposed this plan for dealing with all cases of prostatic obstruction.

IV. My remaining 16 cases are divided into three heads (see Tables IV, V, VI). They all recovered from the operation. The method of shelling out adenomata (Table IV) which I have adopted is the usual one ; the mucous membrane and capsule of the adenoma is divided either by scissors or knife, and the growth itself enucleated with the index finger of the right hand, whilst the prostate and neighbouring parts are steadied by the left hand in the perineum. Most of these tumours are thus easily removed, sometimes entire and sometimes piecemeal. The extent to which the prostatic urethra is injured will depend on the exact situation of the adenoma. In Case 22 the growths were very difficult to enucleate; and fearing that there might be some difficulty in getting the wound to drain properly, I made an incision at the termination of the operation in the perineum. It was possibly to this cause that his subsequent occasional urinary incontinence is due.

V. The hard fibrous prostate calls for a different method of treatment. The very fact of its hardness renders it exceedingly difficult to enucleate. Its boundaries are difficult to define, and it is not so easy to reach as is the large adenoma which bulges into and encroaches on the trigone. It is in this variety that the so-called prostatic collar is usually found. The plan which I have adopted in all these five cases is the same, and it has proved uniformly successful. It was suggested to me by the difficulties which I encountered in Case 23. After having opened the bladder and divided the mucous membrane so as to get at the prostate, I worked away at the process of enucleation for nearly half an hour, until my fingers were getting quite numb, and yet I had separated only about one half of it. At this juncture the patient became very faint, and much to my regret at the time I was forced to abandon any further proceedure that day. The patient was a good deal collapsed after the operation, and for a week or ten days his temperature rose several degrees. At the end of that time several small pieces of prostatic sloughs came away, and he made a good recovery and was able to empty his bladder perfectly. I have seen him once since and he remains well. In all the subsequent cases of this nature I have contented myself with removing only one half of the prostate, and with complete success. The last case is at present under my care. This operation was performed a week since and I feel no anxiety about him.

VI. The last six cases came into a different category. The obstruction in these cases was due not so much to overgrowth as to vasoular change. In the first case when I opened the bladder, the mucous membrane of the trigone, which is usually firmly adherent to it, had prolapsed just like a prolapsed pile into the urethral orifice, and was blocking it. He had suffered a good deal from haemorrhage before the operation, and it was very questionable whether he might not be the subject of a malignant tumour, but the exploration demonstrated the condition of aftairs that I have just related. The cautery was applied freely to the prolapsed mass and a catheter tied into the urethra for several days so as to keep the mass up, and a good recovery resulted.

The next case was one of those that I treated by the Bottini method nearly twelve years ago, and I mention it here because I am confident it belongs to this class of case. The result was a remarkably successful one. I have seen him and examined him on several occasions since, and never found any residual urine. As the actual floor of the bladder and prostate were never inspected by the suprapubic route, it is of course open to doubt whether my inference as to the condition from which he suffered is a correct one. My impression is that some of the successful cases which have been recorded by Bottini and others who have employed his method are due to the fact that it is this class of case which has been successfully treated. Personally I have now quite abandoned this method owing to the uncertainty of the results.

Case 31 was originally under the late Sir W. Savory, and was a very gouty individual. How far his subsequent vesical irritability is due to his gout I am unable to say; he has at any rate had no bleeding to speak of since the operation.

Case 32 is stated to have died a few weeks after leaving the hospital ; he was certainly improved when I last saw him, and I have not been able to find out the cause of his death.

I have not entered into the question of the diagnosis of these various conditions of the prostate, though I am sure it is often possible to come to a conclusion beforehand which variety one has to treat. Practically, when the patient's condition is such as to warrant operative interference, it matters not until the suprapubic opening is made which variety may be present. It is then easy to differentiate the varieties by the sense of touch and sight.

There are two main propositions to which I am anxious to direct attention. The first of these is to the pathological question of the varieties of prostatic obstruction; and the second to the indications to be laid down for operative interference. If we can reduce the mortality, as I believe we can, there is no reason why the operation should not become more general. Of the 33 cases which I have here 
related I have lost but 3 from the operation, and these were all amongst my earlier operations. This gives a mortality of just over 9 per cent. I feel sure that, with growing experience, we shall be able to reduce that mortality still further If so, there is no reason what that condition known as catheter life should not in the main disappear. To some, it is true, it proves a matter of but slight inconvenience, but there are few who would not gladly resume their more youthful habits of micturition, even at the risk of an operation, if they realized to the full the dangers they are incurring from sepsis, quite apart from the weakness and lack of energy which is brought on by frequently rising at night to empty their bladders. If the best results are to be obtained, the operation must be performed before the bladder becomes septic.

\section{REFERENCES.}

Archiv f. Pathologie, cxxvi, r39. ${ }^{2}$ Annales des Maladies des Organes Genito-Urinaires, 1898 , vol. xvi, p. 797. Hypertrophies et Neoplasies Epi theliales de la Prostate.

\section{THE LIFE-SPAN OF FILARIA MEDINENSIS} BY Sir PATRICK MANSON, M.D., K.C.M.G., F.R.S., Medical Adviser to the Colonial Office.

Oppontunities for ascertaining with approximate accuracy the duration of the life-span of the guinea-worm are rare. The annual recurrence of a guinea-worm season in some of the endemic districts affected by that parasite suggests that at least one year, less the three to six weeks necessary for the preparatory metamorphosis in cyclops, must elapse between the date of infection of the human host and the appearance of the mature, embryo-emitting worm at the surface of the body; and, further, that the season of infection is correlated to an annual recurrence of certain hydraulic and thermic conditions favourable to cyclops and to the evolution of the parasite in that crustacean. But it is hard to prove this incontrovertibly from observation in the endemic regions, seeing that it is generally impossible in these localities to exclude the possibility of the infection having taken place at some date prior to or subsequent to the commencement of the postulated year.

As the following cases avoid this source of fallacy they are worth recording.

CASE r.-On May gth, rgo3, I saw, with Dr. Jollye, of Alresford, a gentleman who had just returned from India. He was the subject of multiple guinea-wor'm infection. His story was that he had been shooting in the Decean from February to March, that a guinea-worm had presented in the latter month in his left leg and had caused so much suffering from abscess and sloughing that he had been obliged to stop shooting and had come home. He arrived in England a few days before I saw him. Meanwhile two more guinea-worms had made their appearance, one in each thigh. At the date of my visit both worms were alive and readily emitted their young on the skin in their neighbourhood being douched with cold water. This gentleman believed that he had acquired the parasites in India, but on my pointing out to him the improbability that animals which might be $3 \mathrm{ft}$. in length could attain that size in the course of two or three months he informed me that he had been travelling in Uganda and on the Upper Nile in the spring of the previous year.

CASE 1r.-Four days after I saw this patient Dr. J. A. Mansell Moullin brought to me a gentleman from whose right axilla a guinea-worm was protruding. The parasite had been partly extracted by rolling out; the foot or so of worm still in the tissues was easily withdrawn. It contained, as shown by microscopic examination, living embryos. I asked the patient where he had been travelling the previous year. He replied that lie had been in Uganda and on the Upper Nile in the spring of r9o2, and had not been in the tropics since. "Strange" I said, "only four days ago I saw a patient with guinea-worm who had also been travelling at that
time in Uganda and on the Upper Nile." "Was his name-? "Yes," I replied. "Why," said the patient, "he was my companion from Entebbe to Khartoum."

Manifestly these gentlemen had become infected in the same place and about the same time-that is, approximately, a year before their worms presented at the surface of their bodies.

Subsequently one of the patients was good enough to supply me from his diary with the following particulars about dates and route:

We were in East Africa in roo2, mostly in the neighbourhood of Iake Navaisha, from February ioth to March roth, and on the road between Entebbe and Gondokorro (where the water was very bad in many places), from March ${ }_{17}$ th till May $25^{\text {th }}$, and on a Nile boat between Gondokorro and Khartoum from May 25th till June roth.

The Organizing Committee of the Universal Exhibition to be held at St. Louis has announced that it will refuse admission to all articles actually or potentially hurtful or dangerous. In this class are included patent medicines the formula of which is kept secret.

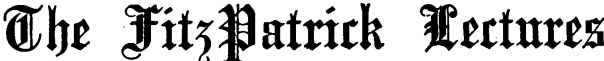

ON THE

\section{HISTORY OF MEDICINE.}

\section{Delivered in the Royal College of Physicians.}

BY JOSEPH FRANK PAYNE, M.D. Fellow and Harveian Librarian.

\section{LECTURE II.}

[ABstract.]

Besides their native herbal medicines and the more scientific therapeutics and pathology which they had borrowed from the Greeks, the Anglo-Saxons made a large use of charms and what are called magical rites in the treatment of disease. It would be a mistake to suppose, as is sometimes thought, that this was their only or chief method of treatment, or that it was in any way.peculiar to the Anglo-Saxons. A great deal of it was taken from the later Greek and Latin medical writers, who show a credulity and superstition quite equal to that of our ancestors.

Again, the magical and superstitious medicine lasted much longer than the Anglo-Saxon period. It went on all through the Middle Ages up till recent times, and is not extinct even at the present day. But it is by no means characteristic of our own country. Indeed, the numerous collections of "folk lore," or what is called "folk medicine," from the peasantry of Continental countries, especially Germany, show that ancient superstitious beliefs of this kind are more prevalent and more inveterate among them than they are among our own people. What is most remarkable is not only that the same general beliefs have survived, but that the very same forms of words have in many cases been preserved for centuries, and may be even now recited in certain places. There is distinct evidence that formulae like those here con sidered were used by people calling themselves doctors at the end of the eighteenth century, and probably even later.

It is very difficult to define precisely what is meant by magical medicine or what by charms. But broadly, they imply a belief in some supernatural efficacy belonging to verbal formulae recited or written under special circumstances or with reference to special objects. Originally, it would seem that this belief implied also the belief in spirits, demons, or some supernatural beings, who could be either conciliated or coerced by the use of certain words. The belief in supernatural personages gradually waned; and in the case we are now considering heathen or mystical conjurations were to a large extent replaced by Christian prayers and benedictions, while the occult rites of unknown origin were superseded by the services of the Church. But the belief in the supernatural power of certain words in curing disease remained.

Without pretending to a complete classification, the various magical processes and charms may be brought under the following heads :

I. Prayers or invocations addressed to medicinal herbs, or to supernatural beings supposed to have power over them.

II. Special verbal formulae or observances employed in collecting the medicinal herbs or other natural remedies.

III. Prayers and mystical words repeated over the patient or written and applied to some part of his body, with or without ordinary remedies. Such words are very often in a foreign tongue unknown to those who use them, such as Latin among the barbarous or uneducated, Greek or Hebrew among the Latins, and so on ; sometimes in a quite unknown language, which have been called Ephesian charms. But they may also be in the vernacular.

IV. Direct conjurations or exorcisms addressed to diseases as if they were evil spirits.

V. Narrative charms-that is, trivial stories relating to sacred or legendary persons who suffered or did something analogous to what the patient is suffering from.

VI. Material magic-that is, the attribution of magical power to certain objects, such as plants or parts of animals, stones, or engraved gems, called amulets, these objects being not used medicinally, but applied in some way to the patient's body.

VII. Transference of disease by a magical formula or ceremony to some animal or material object, or in some way to the outside world.

Examples of all these can be found in older medical literature, 